\title{
ROLE OF SOMATIC ANTIGEN OF VIBRIO CHOLERAE IN ADHESION TO INTESTINAL MUCOSA
}

\author{
D. S. Chitnis, K. D. Sharma and R. S. Kamat \\ Department of Clinical Pathology, Haffkine Institute, Parel, Bombay 400 012, India
}

\begin{abstract}
Summary. The in-vitro adhesion of Vibrio cholerae to intestinal mucous membrane was studied in isolated adult-rabbit ileal loops. Antisomatic antiserum against $V$. cholerae Inaba could inhibit adhesion of three different strains of $V$. cholerae Inaba but had no effect on the adhesion of two different strains of enterotoxigenic NAG vibrios. The antiserum's bacterial agglutinin titre was 320 , its anti-Inaba lipopolysaccharide (LPS) titre was 16000 and its anti-flagellar antibody titre was 3200 . Conversely, anti-live $V$. cholerae Inaba antiserum absorbed with boiled cells of Inaba and devoid of antisomatic antibody, could not inhibit adhesion of the same three strains of $V$. cholerae Inaba. This antiserum had no anti-LPS or bacterial agglutinin activity, but its anti-flagellar antibody titre was 32000 . Thus, ability to inhibit adhesion of $V$. cholerae could be correlated only with antisomatic (anti-LPS) antibody activity. Antisomatic antiserum had no activity against 'adhesin', a $V$. cholerae surface antigen described by Freter. Conversely anti-live $V$. cholerae antiserum absorbed with boiled cells showed anti-adhesin activity even at a dilution of 1 in 200. LPS preparations from $V$. cholerae strain 569B Inaba could inhibit adhesion of two different Inaba strains to the intestinal mucous membrane. It is concluded that the somatic antigen plays a major role in the adhesion of $V$. cholerae to the intestinal mucous membrane.
\end{abstract}

\section{INTRODUCTION}

The mechanism of protection afforded by antibacterial immunity in cholera has remained obscure. In the preceding paper, we have shown that antisomatic antibodies offer protection through inhibition of adhesion of Vibrio cholerae to the intestinal mucosa (Chitnis, Sharma and Kamat, 1981). We have further shown that adhesion of the vibrios to the epithelium is important in the pathogenesis of cholera not only because it prevents them from being eliminated by peristalsis but also because adherent vibrios induce secretion of fluid by smaller amounts of exotoxin. The precise mechanism of bacterial adhesion is far from clear. Freter (1970), and Yancey, Willis and Berry (1979) have suggested that flagellar antigens are involved in adhesion of the vibrios to the mucous membrane. In the present paper we submit evidence to indicate that the somatic antigens of $V$. cholerae play a major role in adhesion. 


\section{MATERIALS AND METHODS}

Bacterial strains. The highly enterotoxigenic strain V. cholerae 569B Inaba, two enterotoxigenic wild strains of $V$. cholerae Inaba isolated from patients with cholera, and two enterotoxigenic strains of NAG vibrios, isolated from patients with diarrhoea were used and are described in the preceding paper (Chitnis et al., 1982).

The antisera used to study inhibition of adhesion of $V$. cholerae included antisomatic (anti-LPS) antiserum, and anti-live cholera absorbed antiserum, i.e., anti-live strain 569B Inaba antiserum absorbed with boiled cells of strain 569B Inaba; the methods of preparation and the characteristics of these sera have been previously described (Chitnis et al., 1982).

Purified soluble lipopolysaccharide (LPS) preparations from V. cholerae strain 569B Inaba and Escherichia coli were prepared and purified by the method of Westphal described by Kwapinski (1972).

In-vitro assay for bacterial adhesion to rabbit intestinal epithelium. A portion of proximal ileum was removed from an adult rabbit and loops of $5 \mathrm{~cm}$ long were prepared in vitro. The loops received the reagents under test, and then each received a challenge inoculum of $10^{6}$ live vibrios suspended in $\mathbf{0 . 2} \%$ gelatin in Hanks's balanced salt solution (BSS). After incubation for $30 \mathrm{~min}$ at room temperature $\left(28^{\circ} \mathrm{C}\right)$ they were cut open, rinsed in $10 \mathrm{ml}$ of phosphate-buffered saline at $p \mathrm{H} 7 \cdot 2$ (PBS) and then washed gently by swirling in $100 \mathrm{ml}$ of PBS in a $250-\mathrm{ml}$ conical flask. After three such washings the walls were homogenised in a tissue homogeniser and a viable count was done to determine the number of colony-forming units ( $\mathrm{cfu}$ ) in the homogenate; this indicated the number of vibrios adherent to the mucous membrane.

Standardisation of the adhesion assay. To test the reproducibility of the adhesion assay, 14 consecutive 5-cm loops of proximal ileum of one rabbit were challenged with $10^{6}$ live $V$. cholerae strain 569B Inaba suspended in $1.0 \mathrm{ml}$ of $0.2 \%$ gelatin in BSS. The results are shown in table I. It can be seen that the number of adherent vibrios ranged from 3200 to 11650 . This degree of variation made the assay unsuitable for the study of inhibition of bacterial adhesion by antisera and other test reagents. However, when the number of adherent vibrios in adjacent loops (i.e., loops 1 and 2, 3 and 4, 5 and 6 etc.) were compared, the differences within each set of adjacent loops were not large. In view of the considerable variation in numbers, the data could not be analysed by parametric statistics. Hence, Wilcoxon's (nonparametric) paired rank sum test as described by Pearson and Hartley (1972) was used, and it could be concluded that the numbers of adherent vibrios in adjacent loops were not significantly different. For testing the ability of the various reagents such as antisera and LPS to inhibit the adhesion of $V$. cholerae to the mucous membrane, the reagents and their appropriate controls were tested in adjacent loops.

Adhesion of $V$. cholerae to human group-O red cells. One $\mathrm{ml} \mathrm{of} 5 \%$ human group-O red cells suspended in Krebs's buffer at $p \mathrm{H} 7.4$ (modified by Freter and Jones, 1976) was mixed with

TABLE I

In-vitro adhesion of $V$. cholerae strain $569 B$ Inaba to the rabbit ileal-loop mucous membrane

\begin{tabular}{cc}
\hline & $\begin{array}{c}\text { Number of adherent } \\
V . \text { cholerae }(\mathrm{cfu})\end{array}$ \\
\hline 1 & 8700 \\
2 & 6850 \\
3 & 4500 \\
4 & 3800 \\
5 & 7900 \\
6 & 6800 \\
7 & 3700 \\
8 & 5000 \\
9 & 5450 \\
10 & 4900 \\
11 & 7700 \\
12 & 9200 \\
13 & 11650 \\
14 & 10200 \\
\hline
\end{tabular}


$5 \times 10^{6}$ live cells of $V$. cholerae Inaba (wild strain) and $1 \mathrm{ml}$ of decomplemented antisomatic antiserum (diluted 1 in 20) or anti-live cholera absorbed antiserum (diluted 1 in 200). Controls containing normal rabbit serum were also set up. The final volume of each suspension was made up to $5 \mathrm{ml}$ with Krebs's buffer. After incubation for $30 \mathrm{~min}$ at $37^{\circ} \mathrm{C}$ the suspensions were spun at $300 \mathrm{~g}$ and the red-cell pellets were washed twice in Krebs's buffer. The final pellet was suspended in $0.1 \%$ gelatin in distilled water to lyse red cells and the lysate was subjected to viable bacterial counts to determine the number of vibrios adherent to red cells.

\section{RESULTS}

Effect of antisomatic antiserum on in-vitro adhesion of vibrios to rabbit intestinal mucous membrane

Sets of alternate ileal loops received $1 \mathrm{ml}$ of decomplemented normal rabbit serum or rabbit antisomatic antiserum (raised against strain 569B Inaba) at a dilution of 1 in 200. An inoculum of $10^{6}$ live vibrios was injected into each loop. After incubation for $30 \mathrm{~min}$ the loops were opened and adherent vibrios were enumerated. The ability of a rabbit antisomatic antiserum raised against $V$. cholerae strain 569B Inaba to inhibit adhesion of the 569B Inaba strain, two other wild Inaba strains and two strains of NAG vibrios was tested in this system. Inhibition of adhesion of NAG vibrios was tested with a 1 in 20 dilution of the antiserum instead of the 1 in 200 dilution used in tests against Inaba vibrios. The data were analysed by Wilcoxon's paired rank sum test. The results (tables II and III) clearly indicate that the antisomatic antiserum could inhibit adhesion of $V$. cholerae Inaba strains but did not inhibit the adhesion of NAG vibrios. Representative results of inhibition studies with a wild Inaba and a NAG vibrio are shown in tables II and III; similar results were observed with two more strains of $V$. cholerae Inaba and one more strain of NAG vibrio. The antiserum had a bacterial agglutinin titre of 320 , an antiInaba-LPS titre of 16000 and an anti-flagellar antibody titre of 3200 as assessed by passive haemagglutination tests (Chitnis et al., 1982).

TABLE II

In-vivo adhesion of $V$. cholerae wild Inaba 1 in the presence of rabbit antisomatic antiserum*

\begin{tabular}{cc}
\hline Number (cfu) of adherent vibrios in \\
\hline $\begin{array}{c}\text { set A } \\
\text { normal presence of }\end{array}$ & $\begin{array}{c}\text { set B } \\
\text { in the presence of } \\
\text { antisomatic antiserum }\end{array}$ \\
\hline 15400 & 4200 \\
23950 & 3750 \\
33500 & 2400 \\
12200 & 2000 \\
19000 & 6500 \\
12800 & 8750 \\
29000 & 12000 \\
\hline
\end{tabular}

\footnotetext{
* Rabbit anti-boiled $V$. cholerae strain 569B Inaba antiserum.

+ Decomplemented sera at a dilution of 1 in 200 .

[Set A is greater than Set B $(p<0 \cdot 001)$ by Wilcoxon's paired rank sum test.]
} 
TABLE III

In-vitro adhesion of NAG vibrio 1 in the presence of rabbit antisomatic antiserum*

\begin{tabular}{cc}
\hline Number (cfu) of adherent vibrios in \\
$\begin{array}{c}\text { set A } \\
\text { in the presence of } \\
\text { normal rabbit serum } \dagger\end{array}$ & $\begin{array}{c}\text { set } \mathbf{B} \\
\text { in the presence of } \\
\text { antisomatic antiserum }\end{array}$ \\
\hline 88500 & 84500 \\
55500 & 81500 \\
44500 & 58000 \\
38500 & 39500 \\
33000 & 28000 \\
31000 & 34000 \\
32000 & 52000 \\
\hline
\end{tabular}

*† See footnotes to table II.

[Set A and B not different by Wilcoxon's paired rank sum test.]

Effect of anti-live cholera absorbed antiserum on in-vitro adhesion of vibrios to rabbit intestinal mucous membrane

Anti-live cholera absorbed antiserum free from anti-LPS activity (Chitnis et al., 1982), failed to inhibit adhesion of $V$. cholerae Inaba strains to the rabbit intestinal mucous membrane. Representative results of inhibition studies with a wild Inaba vibrio are shown in table IV; similar results were observed with the other two Inaba strains. The antiserum had an antibacterial agglutinin titre of less than 2, an anti-Inaba-LPS titre of less than 2 and an anti-flagellar titre of 32000 (Chitnis et al., 1982).

\section{TABLE IV}

In-vitro adhesion of wild $V$. cholerae Inaba 1 in the presence of rabbit anti-live $V$. cholerae antiserum absorbed with boiled cells*

\begin{tabular}{cc}
\hline Number (cfu) of adherent vibrios in \\
$\begin{array}{cc}\text { set A } A \text { set B } \\
\text { in the presence of } \\
\text { normal rabbit serum } \dagger\end{array}$ & $\begin{array}{c}\text { se presce of } \\
\text { in the absorbed antiserum* }\end{array}$ \\
\hline 43250 & 40750 \\
51000 & 34750 \\
73250 & 38250 \\
71500 & 53250 \\
145000 & 94250 \\
125500 & 78250 \\
130500 & 141000 \\
\hline
\end{tabular}

* Rabbit anti-live $V$. cholerae 579B Inaba antiserum absorbed with boiled Inaba cells. $\dagger$ Decomplemented sera at a dilution of 1 in 20.

[Set $A$ and $B$ not different by Wilcoxon's paired rank sum test.]

Effect of Inaba LPS on the in-vitro adhesion of vibrios to rabbit intestinal mucous membrane

Before testing of the effect of Inaba LPS on adhesion of $V$. cholerae to the rabbit 
TABLE V

In-vitro adhesion of wild $V$. cholerae Inaba 1 in the presence of E. coli LPS* and Hanks's gelatin $\dagger$

\begin{tabular}{|c|c|}
\hline \multicolumn{2}{|c|}{ Number (cfu) of adherent vibrios in } \\
\hline $\begin{array}{c}\text { set } \mathbf{A} \\
\text { in the presence } \\
\text { of } E \text {. coli } \text { LPS }\end{array}$ & $\begin{array}{c}\text { set B } \\
\text { in the presence of } \\
\text { Hanks's gelatin }\end{array}$ \\
\hline $\begin{array}{r}95000 \\
61750 \\
79250 \\
91750 \\
69000 \\
71500 \\
118750\end{array}$ & $\begin{array}{r}75000 \\
44500 \\
63250 \\
120000 \\
94750 \\
96500 \\
132250\end{array}$ \\
\hline
\end{tabular}

intestinal mucous membrane, it was essential to show that LPS per se had no non-specific effect on adhesion of $V$. cholerae to the mucous membrane. A $1-\mathrm{ml}$ volume of $E$. coli LPS at a concentration of $2.0 \mathrm{mg} / \mathrm{ml}$ in BSS containing $0.2 \%$ gelatin was injected into in-vitro rabbit intestinal loops. Alternate loops received $1.0 \mathrm{ml}$ of LPS or 1.0 of $0.2 \%$ gelatin in BSS. Each loop then received $10^{6}$ live cells of a wild $V$. cholerae Inaba strain. After incubation for $30 \mathrm{~min}$, the loops were opened and washed and the adherent vibrios were enumerated. The numbers of adherent vibrios in the two sets of loops, i.e., those with and without $E$. coli LPS, were not significantly different (table V). This indicates that LPS per se has no non-specific effect on bacterial adhesion to the mucous membrane.

The effect of homologous Inaba LPS at a concentration of $2.0 \mathrm{mg} / \mathrm{ml}$ was then tested against $V$. cholerae strain 569B Inaba and one wild Inaba strain. Representative results of inhibition studies with one wild Inaba strain are shown in table VI; similar results were observed with the 569B Inaba strain. It

TABLE VI

In-vitro adhesion of wild $V$. cholerae Inaba 1 in the presence of Inaba LPS* and Hanks's gelatin $\dagger$

\begin{tabular}{cc}
\hline $\begin{array}{c}\text { Number (cfu) of adherent vibrios in } \\
\text { set A } \\
\begin{array}{c}\text { in the presence } \\
\text { of Hanks's gelatin }\end{array}\end{array}$ & $\begin{array}{c}\text { in the } \mathbf{B} \\
\text { Inaba LPS } \\
\text { Inabe }\end{array}$ \\
\hline 206750 & 44000 \\
101250 & 63250 \\
157500 & 74500 \\
148500 & 38500 \\
110500 & 28000 \\
122750 & 13750 \\
187500 & 39000 \\
\hline
\end{tabular}

$*+$ See footnotes to table $\mathrm{V}$.

[Set A is greater than Set B $(p<0 \cdot 001)$ by Wilcoxon's paired rank sum test.] 
TABLE VII

Adhesion of $V$. cholerae Inaba to human group-O red cells in the presence of antisomatic antiserum

\begin{tabular}{|c|c|c|c|}
\hline $\begin{array}{l}\text { Number of vibrios adherent* } \\
\text { to red cells in the } \\
\text { presence of normal rabbit } \\
\text { serum diluted } 1 \text { in } 20\end{array}$ & $\begin{array}{c}\text { Mean } \\
( \pm 90 \% \\
\text { confidence } \\
\text { limit })\end{array}$ & $\begin{array}{c}\text { Number of vibrios adherent* } \\
\text { to red cells in the } \\
\text { presence of antisomatic } \\
\text { antiserum diluted } 1 \text { in } 20\end{array}$ & $\begin{array}{c}\text { Mean } \\
( \pm 90 \% \\
\text { confidence } \\
\text { limit })\end{array}$ \\
\hline $\begin{array}{l}4.1 \times 10^{5} \\
4.4 \times 10^{5} \\
3 \cdot 7 \times 10^{5} \\
3.4 \times 10^{5} \\
3.0 \times 10^{5} \\
3.8 \times 10^{5}\end{array}$ & $\begin{array}{c}3.7 \times 10^{5} \\
\left( \pm 0.64 \times 10^{5}\right) \dagger\end{array}$ & $\begin{array}{l}3.8 \times 10^{5} \\
2 \cdot 7 \times 10^{5} \\
4 \cdot 3 \times 10^{5} \\
3 \cdot 4 \times 10^{5} \\
3 \cdot 3 \times 10^{5} \\
2 \cdot 6 \times 10^{5}\end{array}$ & $\begin{array}{c}3.35 \times 10^{5} \\
\left( \pm 0.67 \times 10^{5}\right) \dagger\end{array}$ \\
\hline
\end{tabular}

* Number of vibrios retained by red-cell pellet from $1 \mathrm{ml}$ of $5 \%$ suspension of red blood cells.

$\dagger$ Difference not significant.

is clear that Inaba LPS specifically inhibited adhesion of the $V$. cholerae Inaba strains.

\section{Anti-adhesion activity of the antisera}

This was assayed by testing the ability of the two antisera to inhibit adhesion of $V$. cholerae to human group-O red cells. The results given in table VII show that the antisomatic antiserum at a 1 in 20 dilution did not inhibit the adhesion, whereas the anti-live cholera absorbed antiserum, devoid of anti-LPS activity, inhibited adhesion of $V$. cholerae to human group-O red cells even at a dilution of 1 in 200 (table VIII). This antiserum had an antiflagellar antibody titre of 32000 .

\section{Studies on possible clumping effects}

It could be argued that the antisomatic antiserum used in our experiments may cause clumping of the bacteria by the agglutination reaction, and that the

\section{TABLE VIII}

Adhesion of $V$. cholerae Inaba to human group- $O$ red cells in the presence of anti-live $V$. cholerae antiserum absorbed with boiled Inaba cells

\begin{tabular}{|c|c|c|c|c|}
\hline $\begin{array}{l}\text { Number of vibrios* } \\
\text { adherent to red cells } \\
\text { in the presence of normal } \\
\text { rabbit serum } \dagger\end{array}$ & $\begin{array}{l}\text { Mean } \\
( \pm 99 \% \\
\text { confidence } \\
\text { limits })\end{array}$ & $\begin{array}{c}\text { Number of vibrios* } \\
\text { adherent to red cells } \\
\text { in the presence of anti- } \\
\text { live } V \text {. cholerae } \\
\text { antiserum absorbed with } \\
\text { boiled cells } \dagger\end{array}$ & $\begin{array}{c}\text { Mean } \\
( \pm 99 \% \\
\text { confidence } \\
\text { limits })\end{array}$ & $\begin{array}{l}\text { Percentage } \\
\text { inhibition }\end{array}$ \\
\hline $\left.\begin{array}{r}6.8 \times 10^{5} \\
8.65 \times 10^{5} \\
9.4 \times 10^{5} \\
9.8 \times 10^{5} \\
1.2 \times 10^{6} \\
1.2 \times 10^{6}\end{array}\right\}$ & $\begin{array}{c}9.777 \times 10^{5} \\
\left( \pm 2.416 \times 10^{5}\right)\end{array}$ & $\begin{array}{r}2.8 \times 10^{4} \\
1.2 \times 10^{4} \\
1.0 \times 10^{4} \\
3.8 \times 10^{4} \\
5.4 \times 10^{4} \\
7 \cdot 16 \times 10^{4}\end{array}$ & $\begin{array}{c}3.56 \times 10^{4} \\
\left( \pm 4.03 \times 10^{4}\right)\end{array}$ & $96 \cdot 4$ \\
\hline
\end{tabular}

* Number of vibrios retained by red cell pellet of $1 \mathrm{ml}$ of $5 \%$ suspension of red blood cells.

$\dagger$ Both sera tested at a dilution of 1 in 200. 
reduction in the number of adherent vibrios attributed to the antiserum was due to clumping of the bacteria and not to inhibition of adhesion. Indeed if this were true, the observed in-vitro effects of the antisomatic antiserum may have no in-vivo relevance, because the local antibody in the gastro-intestinal tract is $\operatorname{IgA}$ and is a poor agglutinogen. To resolve the issue of bacterial clumping, $10^{6}$ live $V$. cholerae wild Inaba-I, were incubated in $1.0 \mathrm{ml}$ of different dilutions of the antisomatic antiserum at $37^{\circ} \mathrm{C}$ for $45 \mathrm{~min}$. The bacterial suspensions were then diluted and plated out to determine the number of cfu in each suspension. No reduction in the cfu count was observed even at a 1 in 10 dilution of the antiserum.

\section{Discussion}

Many investigators (Freter, 1970; Schrank and Verwey, 1976; Holmgren and Svennerholm, 1977) have reported that antisomatic $V$. cholerae antibodies offer passive protection, thus implying a major role for the somatic antigens in bacterial adhesion to the intestinal mucous membrane. However the relative importance of the various bacterial surface molecules in the adhesion process is still in doubt. Holmgren and Svennerholm (1977) have indicated a major role for the somatic antigen, whereas Yancey et al. (1979) presented evidence in favour of the flagellar antigens. Freter and Jones (1976) demonstrated that a flagellar protein, 'adhesin', is important in the adhesion of $V$. cholerae to the intestinal epithelial brush border. Because most of these conclusions are based on studies with different experimental systems, comparison of the data is very difficult.

In the preceding paper we reported that an antisomatic antiserum with predominant anti-Inaba LPS antibodies passively protected adult-rabbit ileal loops against challenge with live $V$. cholerae Inaba strains (Chitnis et al., 1982). However, the anti-live cholera absorbed antiserum free from anti-LPS antibodies failed to protect. The remarkable point is that the absorbed antiserum retained most of the anti-flagellar activity (passive haemagglutination titre, 32000 ).

Our present findings indicate that antisomatic antiserum against $V$. cholerae Inaba was effective at a dilution of 1 in 200 in preventing the in-vitro adhesion of the three different strains of $V$. cholerae Inaba to rabbit intestinal mucous membrane but had no effect on the adhesion of two test strains of NAG vibrios. The antiserum had an anti-LPS titre of 16000 and an anti-flagellar antibody titre of 32000 as assessed by passive haemagglutination tests. However, the anti-live cholera absorbed antiserum even at a dilution of 1 in 20 could not block the adhesion of the same three strains of $V$. cholerae Inaba to the intestinal epithelium, despite the fact that its potent anti-flagellar activity was retained. Thus, the inhibition of in-vitro adhesion of $V$. cholerae to rabbit ileal mucous membrane correlated with the antisomatic (anti-LPS) antibody activity of the antiserum and not with its antiflagellar activity. The studies on possible clumping effects clearly indicate that the observed in-vitro reduction in the number of vibrios adherent to the mucous membrane brought about by the antisomatic antiserum is not due to bacterial clumping. 
It is also possible that the observed in-vitro effects of the antisomatic antiserum on $V$. cholerae adhesion may be due to inhibition of motility, because the non-motile and the feebly motile strains have been shown to adhere to the mucous membrane poorly (Bhattacharjee and Srivastava, 1979). This can be ruled out because the anti-live cholera absorbed antiserum having an anti-LPS titre of less than 2 and anti-flagellar titre of 32000 could not inhibit bacterial adhesion even at a dilution of 1 in 20 .

The two antisera were also checked for antibody activity against the flagellar protein 'adhesin' reported by Freter and Jones (1976) to be important in the adhesion of $V$. cholerae to the intestinal epithelial brush borders. The antisomatic antiserum, which could block the adhesion of $V$. cholerae to the ileal mucous membrane at 1 in 200 dilution, did not have any anti-adhesin activity even at a dilution of 1 in 20 . Conversely, the anti-live cholera absorbed antiserum showed anti-adhesin activity at a dilution of 1 in 200 , but it could not block the adhesion of $V$. cholerae to the mucous membrane even at a dilution of 1 in 20 . Thus, it can be concluded that in our experimental system flagellar antigens did not play a major role in the adhesion of $V$. cholerae to the adult rabbit ileal mucous membrane.

It could be argued that the observed blockade by the antisomatic antiserum was due to steric hindrance after interaction between the epithelial cell surface and a hypothetical bacterial surface molecule other than LPS. Because Inaba LPS effectively blocked the adhesion of $V$. cholerae Inaba, we conclude that the somatic antigens play an important role in the adhesion of $V$. cholerae to the mucous membrane.

We do not wish to imply that bacterial surface entities other than the somatic antigen have no role in the adhesion of $V$. cholerae. The reported evidence and our data together indicate that more than one vibrio surface molecule may participate in the adhesion to the mucous membrane. However, all need not be equally important. Because passive protection could be induced by antisomatic antibodies and not by anti-flagellar antibodies (Chitnis et al., 1982), it is proposed that the somatic antigens play a major role in the interaction between the mucous membrane and the vibrios. We feel that the flagellar antigens probably play a secondary role in stabilising the adhesion primarily brought about through the somatic antigens.

In the light of the evidence of this and the preceding paper (Chitnis et al., 1981), the limitations of the conventional formalin-killed cholera vaccine (Joo', 1974) still need to be explained. We have clearly demonstrated that antisomatic antibodies, if present in intestinal secretions, could be capable of offering excellent protection (Chitnis et al., 1981). The conventional cholera vaccine given by the subcutaneous route probably cannot induce sustained production of effective secretory antibodies in the gastro-intestinal tract. If this is true, any other form of vaccine given by the subcutaneous route is also likely to be unsatisfactory. This would include toxoid vaccines; indeed, the results of a recent field trial with a toxoid vaccine are as unsatisfactory as those obtained with conventional cholera vaccines (Curlin et al., 1975). 


\section{REFERENCES}

BhattacharJeE, J. W. AND SRIVASTaVa, B. S. 1979. Adherence of wild-type and mutant strains of $V$. cholerae to normal and immune intestinal tissue. Bull. Wld Hlth Org., 57, 123.

Chitnis, D. S., Sharma, K. D. and Kamat, R. S. 1982. Role of bacterial adhesion in the pathogenesis of cholera. J. med. Microbiol., 15, 43.

Curlin, G., Levine, R., Aziz, K. M. A., Rahman, M. A. S. M. and Vervey, W. F. 1975. Field trial of cholera toxoid. In Proceedings of 11 th joint conference on cholera, US-Japan Cooperative Medical Science Program, New Orleans, US Dept. of Health, Education and Welfare, Washington DC, p. 314.

FRETER, R. 1970. Mechanism of action of intestinal antibody in experimental cholera. II. Antibody-mediated antibacterial reaction at the mucosal surface. Infect. Immun., 2, 556.

FRETER, R. AND JONES, G. W. 1976. Adhesive properties of Vibrio cholerae: nature of the interaction with intact mucosal surfaces. Infect. Immun., 14, 246.

Holmgren, J. AND SVENNERHOLM, A. M. 1977. Mechanism of disease and immunity in cholera: a review. J. infect. Dis., 135, suppl, S-105.

Joo', I. 1974. Cholera vaccines. In Cholera, edited by D. Barua and W. Burrows, Saunders, Philadelphia, p. 1.

KWAPINSKI, J. 1972. Methodology of immunochemical and immunological research, Wiley Interscience, NY, p. 80.

Pearson, E. S. AND Hartley, H. O. 1972. Biometrica tables for statisticians, vol. 2, Cambridge University Press, Cambridge, p. 228.

SChrank, G. D. AND Verwey, W. F. 1976. Distribution of cholera organisms in experimental Vibrio cholerae infection: proposed mechanisms of pathogenesis and antibacterial immunity. Infect. Imm., 13, 195.

YANCEY, R. J., WILlIS, D. L. AND BERRY, L. J. 1979. Flagella-induced immunity against experimental cholera in adult rabbits. Infect. Immun., 25, 220. 